\title{
Relationship between the clinical assessment of maxillary and mandibular complete denture stability and denture-bearing area towards the patient's satisfaction level
}

\author{
"Putri Welda Utami Ritonga*, Luveena Loshini Prabakaran* \\ *Department of Prosthodontics Faculty of Dentistry University of North Sumatra, Indonesia
}

\begin{abstract}
Introduction: The dentist's evaluation of complete denture often differs from the patient's evaluation. Dentists are more prioritising the clinical aspects of the dentures, such as vertical dimension, aesthetical, stability, and denture-bearing area, while patients are more prioritising their satisfaction based on aspects such as aesthetical, mastication, comfort, and phonetic ability. The purpose of this study was to determine the relationship between the stability of maxillary and mandibular denture-bearing area towards the complete denture patient's satisfaction level. Methods: This study was a cross-sectional study with purposive sampling as the sampling method. The sample of this study was as much as 30 complete denture patient. The patients were interviewed using a questionnaire in each of the patient's house, to obtain a more honest patient's satisfaction assessment on the dentures, without being affected by any clinical environment and assessment. The interview was conducted before the clinical evaluation was performed. The statistical analysis was performed using the Fisher's test. The stability of the denture-bearing area was evaluated clinically. Mastication ability and patient's comfort were evaluated using a questionnaire. Results: A significant relationship was found between the stability of maxillary denture-bearing area towards mastication $(p=0.012)$, and the stability of mandibular denturebearing area towards mastication $(p=0.029)$; while no significant relationship was found between the stability of maxillary denture-bearing area towards the patient's comfort $(p=0,051)$, and the stability of mandibular denture-bearing area towards the patient's comfort $(p=0,547)$. Conclusion: There was a relationship between the stability of maxillary and mandibular denture-bearing area towards the patient's masticatory satisfaction level. However, the relationship between the stability of maxillary and mandibular denture-bearing area towards the patient's comfort was not found.
\end{abstract}

Keywords: Complete denture, clinical evaluation, denture-bearing area, patient’s satisfaction.

p-ISSN: 1979-0201; e-ISSN: 2549-6212; Available from: http://jurnal.unpad.ac.id/pid/editor/submission/18322

DOI: http://dx.doi.org/10.24198/pjd.vol30no2.18322

Submission: February 2, 2017; Accepted: Mar 27, 2018; Published online: July 31, 2018

\#Corresponding author: Putri Welda Utami Ritonga, Department of Prosthodontics, Faculty of Dentistry, University of North Sumatra, Indonesia

Dr. T. Mansur No. 9, Padang Bulan, Medan, Indonesia. Phone: +62 878-6814-3214. E-mail: welldone puti@yahoo.com 


\section{INTRODUCTION}

Complete tooth loss is a condition where individual experiences the loss of all original teeth caused by caries, periodontal diseases, and trauma. ${ }^{1}$ Complete Denture (CD) is a treatment often selected for the total tooth loss case due to relatively low maintenance costs compared to overdenture or implant supported treatment.

The majority of patients with complete denture treatment are satisfied with the dentures they're using, but a small percentage, approximately $10-15 \%$ of patients, still feel dissatisfied with their complete denture even though it has been created according to all predefined criteria. $^{2}$ Therefore, post-treatment evaluation is important to detect the cause of patient's dissatisfaction and simultaneously increase the patient's satisfaction levels towards the complete denture treatment. Post-treatment evaluation of complete denture can be classified into two namely, dentist's evaluation and patient's evaluation. Patient's evaluation is based on the patient's satisfaction feelings on the phonetics, mastication, aesthetics, and comfort. Dentist's evaluation is based on the clinical assessment of the vertical dimension, aesthetic, stability, and denture-bearing area of the patient. Dentists prefer the quality of denture, but patients prefer the comfort, functional, and appearance aspects.

Denture stability has an important role in the success of complete denture treatment. Improper denture stability can affect the effectiveness of the complete denture because it can leads to detachment of the denture when given pressure thus disrupting the mastication process. The research conducted by Brunello and Mandikos in 1998 suggested that good complete denture stability had a positive effect towards the patient's satisfaction levels. The results of their study indicated a correlation between complete denture stability with the patient's satisfaction regarding mastication and food options. ${ }^{3}$

Denture-bearing area also affects the complete denture treatment success. An optimal denture-bearing area is important to distribute an equal pressure to not triggering severe resorption and disturbing the patient's comfort.
The research conducted by Celebic et al. in 2003 showed a positive correlation between the quality of the denture-bearing area and the patient's comfort when wearing the complete denture. ${ }^{2}$ The purpose of this study was to determine the relationship between the stability of maxillary and mandibular denture-bearing area towards the complete denture patient's satisfaction level.

\section{METHODS}

Design of this research was cross-sectional. The population in this research were patients using complete denture made by dentistry students in Prosthodontics Clinic Secretariat of Academic Dental Hospital Faculty of Dentistry University of North Sumatra, Medan, from January 2013 to June 2015. The sampling methods used was the non-probability method with purposive sampling technique. The number of research samples was as much as 30 people according to the minimum number set by Bailey and Gay. ${ }^{10}$ Data collection method was performed by direct interview using questionnaires and complete denture clinical examination.

Clinical examination of the complete denture was performed by giving horizontal tensions alternately on the occlusal surface of the left and right premolars (Figure 1); while the clinical examination of the denture-bearing area was performed by observing the alveolar ridge shape (Figure 2). The 5 score was given to an excellent denture; the 4 score was given to a good denture; the 3 score was given to a moderate denture; the 2 score was given to a poor denture; and the 1 score was given to a worse denture.

Evaluation of the patient's satisfaction level was performed using a questionnaire regarding mastication and comfort. The 5 score was given to a very satisfying denture; the 4 score was given to a satisfying denture; the 3 score was given to a moderately satisfying denture; the 2 score was given to a dissatisfying denture; and the 1 score was given to a very dissatisfying denture. The analysis of the relationship of clinical assessment towards the complete denture patient's satisfaction level in the Academic Dental Hospital Faculty of Dentistry University of North Sumatra 
was performed using the Fisher test because the data was not normally distributed.

\section{RESULTS}

Related to the maxillary denture-bearing area stability, the mastication satisfactory of complete denture patient was found mostly at the level of very satisfying, in as much as 9 patients (30\%), which was in line to the clinical assessment which was considered of having very good stability. However, some patients were not satisfied with their complete denture regarding the mastication problem, in as much as 2 patients $(6.7 \%)$, even though the clinical assessment was considered of having good stability.

Related to the mandibular denture-bearing area stability, the mastication satisfactory of complete denture patient was found mostly at the level of very satisfying, in as much as 5 patients $(16.7 \%)$, which was in line to the clinical assessment which was considered of having very good stability. However, some patients were not satisfied with their complete denture regarding the mastication problem, in as much as 2 patients (6.7\%), even though the clinical assessment was considered of having medium stability.

Related to the maxillary denture-bearing area stability, the comfort satisfactory of complete denture patient was found mostly at the level of very satisfying, in as much as 7 patients (23.7\%), which was in line to the clinical assessment which was considered of having very good stability. However, some patients were not satisfied with their complete denture regarding the comfort problem, in as much as 1 patient (3.3\%), even though the clinical assessment was considered of having good stability. While related to the mandibular denture-bearing area stability, the comfort satisfactory of complete denture patient was found mostly at the level of dissatisfying, in as much as 4 patients (13.3\%), even though the clinical assessment was considered of having good stability. As much as 2 patients (6.7\%) feel very dissatisfied regarding the comfort of their mandibular complete denture-bearing area, even though the clinical assessment was considered of having medium stability; and as much as 1 patient
(3.3\%) also feel very dissatisfied regarding the comfort of their mandibular complete denturebearing area, in the good stability complete denture based on the clinical assessment.

The Fisher test result showed that there was a significant $(p<0.05)$ relationship between the stability of the maxillary and mandibular denturebearing area towards the patients' satisfaction level in mastication, but showed no relationship between the maxillary and mandibular denturebearing area on patient towards the patients' satisfaction level in comfort.

\section{DISCUSSION}

The results of this study indicated that the patient's satisfaction level of mastication was mostly very satisfied. The results of this study were consistent with previous studies showed that most complete denture patients were very satisfied towards their mastication satisfactory. ${ }^{2}$ This result may occur because mastication is the main cause that encourages patients to get a complete denture treatment due to complete tooth loss had minimised the food consumption, which interferes with the nutrition intake. The use of complete denture helps to improve the mastication function so that the patients will be able to consume food without any difficulties. ${ }^{9}$

From the results of this study also found that the patient's satisfaction level in comfort of the maxillary complete denture-bearing area was found mostly in a satisfying level. This result was consistent with previous studies stated that most complete denture patients felt satisfied and very satisfied towards the comfort of their maxillary complete denture-bearing area. Therefore, the pressure obtained from the maxillary complete denture-bearing area has proven to be able to be distributed evenly, so it does not cause any discomfort. ${ }^{6}$

The patient's satisfaction level in comfort of the mandibular complete denture-bearing area was found mostly in a dissatisfying level. This result was consistent with previous studies stated that mandibular complete denture-bearing area often causes problems compared to the maxillary denture-bearing area. $^{9}$ This condition may be 
Table 1. Distribution of complete denture clinical assessment based on the patient's satisfaction level at Academic Dental Hospital Faculty of Dentistry University of North Sumatra

\begin{tabular}{|c|c|c|c|c|c|c|c|c|c|c|c|}
\hline \multirow[t]{2}{*}{ Clinical assessment } & \multicolumn{10}{|c|}{ Patient's satisfaction level } & \multirow[t]{4}{*}{ Total } \\
\hline & & & & $\mathrm{Ma}$ & cati & satisfa & tory & & & & \\
\hline \multirow{2}{*}{ Stability } & \multicolumn{2}{|c|}{1 score } & \multicolumn{2}{|c|}{2 score } & \multicolumn{2}{|c|}{3 score } & \multicolumn{2}{|c|}{4 score } & \multicolumn{2}{|c|}{5 score } & \\
\hline & $\mathbf{N}$ & $\%$ & $\mathbf{N}$ & $\%$ & $\mathrm{~N}$ & $\%$ & $\mathbf{N}$ & $\%$ & $\mathbf{N}$ & $\%$ & \\
\hline \multicolumn{12}{|c|}{ Maxillary } \\
\hline 1 score & 0 & 0 & 0 & 0 & 0 & 0 & 0 & 0 & 0 & 0 & 0 \\
\hline 2 score & 1 & 3.3 & 0 & 0 & 0 & 0 & 0 & 0 & 0 & 0 & 1 \\
\hline 3 score & 0 & 0 & 1 & 3.3 & 2 & 6.7 & 1 & 3.3 & 0 & 0 & 4 \\
\hline 4 score & 0 & 0 & 2 & 6.7 & 2 & 6.7 & 4 & 13.3 & 2 & 6.7 & 10 \\
\hline 5 score & 0 & 0 & 0 & 0 & 1 & 3.3 & 5 & 16.7 & 9 & 30 & 15 \\
\hline Total & 1 & 3.3 & 3 & 10 & 5 & 16.7 & 10 & 33.3 & 11 & 36.7 & 30 \\
\hline \multicolumn{12}{|c|}{ Mandibular } \\
\hline 1 score & 1 & 3.3 & 1 & 3.3 & 0 & 0 & 0 & 0 & 0 & 0 & 2 \\
\hline 2 score & 0 & 0 & 1 & 3.3 & 1 & 3.3 & 1 & 3.3 & 0 & 0 & 3 \\
\hline 3 score & 0 & 0 & 0 & 0 & 4 & 13.3 & 2 & 6.7 & 3 & 10 & 9 \\
\hline 4 score & 0 & 0 & 0 & 0 & 0 & 0 & 4 & 13.3 & 3 & 10 & 7 \\
\hline 5 score & 0 & 0 & 1 & 3.3 & 0 & 0 & 3 & 10 & 5 & 16.7 & 9 \\
\hline Total & 1 & 3.3 & 3 & 10 & 5 & 16.7 & 10 & 33.3 & 11 & 36.7 & 30 \\
\hline \multirow{2}{*}{ Denture-bearing area } & \multicolumn{10}{|c|}{ Comfort satisfactory } & \\
\hline & $\mathbf{N}$ & $\%$ & $\mathbf{N}$ & $\%$ & $\mathrm{~N}$ & $\%$ & $\mathbf{N}$ & $\%$ & $\mathbf{N}$ & $\%$ & \\
\hline \multicolumn{12}{|c|}{ Maxillary } \\
\hline 1 score & 0 & 0 & 0 & 0 & 0 & 0 & 0 & 0 & 0 & 0 & 0 \\
\hline 2 score & 0 & 0 & 0 & 0 & 0 & 0 & 0 & 0 & 1 & 3.3 & 1 \\
\hline 3 score & 0 & 0 & 0 & 0 & 1 & 3.3 & 3 & 10 & 0 & 0 & 4 \\
\hline 4 score & 1 & 3.3 & 1 & 3.3 & 1 & 3.3 & 8 & 26.7 & 3 & 10 & 14 \\
\hline 5 score & 0 & 0 & 2 & 6.7 & 1 & 3.3 & 1 & 3.3 & 7 & 23.3 & 11 \\
\hline Total & 1 & 3.3 & 3 & 10 & 3 & 10 & 12 & 40 & 11 & 36.7 & 30 \\
\hline \multicolumn{12}{|c|}{ Mandibular } \\
\hline 1 score & 1 & 3.3 & 1 & 3.3 & 0 & 0 & 1 & 3.3 & 0 & 0 & 3 \\
\hline 2 score & 1 & 3.3 & 3 & 10 & 1 & 3.3 & 2 & 6.7 & 0 & 0 & 7 \\
\hline 3 score & 0 & 0 & 3 & 10 & 0 & 0 & 0 & 0 & 2 & 6.7 & 5 \\
\hline 4 score & 1 & 3.3 & 4 & 13.3 & 2 & 6.7 & 1 & 3.3 & 3 & 10 & 11 \\
\hline 5 score & 0 & 0 & 1 & 3.3 & 0 & 0 & 0 & 0 & 3 & 10 & 4 \\
\hline Total & 3 & 10 & 12 & 40 & 3 & 10 & 4 & 13.3 & 8 & 26.7 & 30 \\
\hline
\end{tabular}

caused by to the different levels and direction of bone resorption between the maxilla and mandible causing changes in the relationships.

The Fisher test result for the stability of maxillary denture-bearing area showed a significant $(p<0.05)$ relationship between the stability of the maxillary denture bearing-area with $p=0.012$, and the mandibular denturebearing area with $p=0.029$, towards mastication satisfactory level. These results indicated that the better stability of the maxillary denture-bearing area, the better the level of patient's mastication satisfactory level. This condition occurred because complete denture stability plays an important role in placing the complete denture in its position. ${ }^{1}$

Complete denture mobility affects the patient's mastication satisfactory. Complete denture with poor stability will shift whenever given 
Table 2. Correlation test between clinical assessment and complete denture patient's satisfaction level at Academic Dental Hospital Faculty of Dentistry University of North Sumatra

\begin{tabular}{|c|c|c|}
\hline Clinical assessment & Patient's satisfaction level & P \\
\hline Maxillary stability & Mastication & $0.012^{*}$ \\
\hline Mandibular stability & Mastication & $0.029^{*}$ \\
\hline Maxillary denture-bearing area & Maxillary comfort & 0.051 \\
\hline Mandibular denture-bearing area & Mandibular comfort & 0.547 \\
\hline \multicolumn{2}{|c|}{} \\
\hline \multicolumn{2}{|c|}{ "significant relationship at the p-value < 0.05 ) } \\
\hline
\end{tabular}

horizontal pressure, especially during mastication, which will disrupt the mastication process. This condition is likely because mastication is a process involving both jaws. The result of this study was consistent with the previous study stated that good complete denture stability affected the patient's mastication satisfactory positively. ${ }^{6}$

The Fisher test result for the stability of maxillary denture-bearing area showed no significant $(p>0.05)$ relationship between the stability of the maxillary denture bearing-area with $p=0.051$, towards the comfort satisfactory level. This result indicated that maxillary comfort was not affected by the denture-bearing area. This condition is probably caused by the assessed denture-bearing area in this study was the alveolar ridge shape only. The compressibility of the mucosa in the edentulous ridge was not assessed in this study. Previous studies have suggested that mucosal compressibility in the edentulous ridge was strongly related with denture retention. ${ }^{9}$

The Fisher test result for stability of the mandibular denture-bearing area showed no significant $(p>0.05)$ relationship between stability of the mandibular denture bearing-area towards the comfort satisfactory level, with $p=0.0547$. This result indicated that the mandibular comfort was not affected by the denture-bearing area. The result of this study was consistent with previous studies stated that there was no significant relationship between mandibular denturebearing area towards the mandibular comfort. 2 This condition was likely because the alveolar ridge resorption is a chronic process occurs after tooth loss. The alveolar bone resorption level will reach the highest when tooth loss occurs thus the complete denture must be applied immediately. The rather long time neuromuscular adaptation period will cause the mandibular complete denture-bearing area moves easily so that it will be able to injure the oral mucosa and at the same time cause discomfort.

\section{CONCLUSION}

There was a relationship between the stability of maxillary and mandibular denture-bearing area towards the patient's masticatory satisfaction level. However, the relationship between the stability of maxillary and mandibular denturebearing area towards the patient's comfort was not found.

\section{REFERENCES}

1. Peltzer K, Hewlett $S$, Yawson AE, Moynihan $P$, Preet R, Wu F, et al. Prevalence of Loss of All Teeth (Edentulism) and Associated Factors in Older Adults in China, Ghana, India, Mexico, Russia and South Africa. Int J Environ Res Public Health. 2014; 11(11): 11308-24. DOI: 10.3390/ijerph111111308

2. Celebić A, Valentić-Peruzović M, Stipetić J, Delić Z, Stanicić T, Ibrahimagić L. The Patient's and the Therapist's Evaluation of Complete Denture Therapy. Coll Antropol. 2000; 24 Suppl 1: 71-7.

3. Shah AA. Quality of dentures and patient satisfaction. PJMHS. 2009; 3(2): 140-2.

4. Memon MR, Ghani F, Shahzad M. Functional assessment of removable complete dentures. Pakistan Oral Dent J. 2013; 33(3): 563-5.

5. Stunic MK, Kranjčić J, Persic S, Lončar A. The influence of upper denture stability on patient's satisfaction. Acta Stomatol Croat. 2012; 46(2): 135-41. 
6. Rostiny. The correction of occlusal vertical dimension on tooth wear. Dent J (Maj Ked Gigi). 2007; 40(4): 161-4.

7. Basting RT, da Trindade Rde C, Florio FM. Comparative study of smile analysis by subjective and computerized methods. Oper Dent. 2006; 31(6): 652-9. DOI: 10.2341/06-24

8. Farias-Neto A, Carreiro Ada F. Changes in patient satisfaction and masticatory efficiency during adaptation to new dentures. Compend
Contin Educ Dent. 2015; 36(3): 174-7.

9. Ribeiro JA, de Resende CM, Lopes AL, FariasNeto A, Carreiro Ada F. The influence of mandibular ridge anatomy on treatment outcome with conventional complete dentures. Acta Odontol Latinoam. 2014; 27(2): 53-7. DOI: $10.1590 /$ S1852-48342014000200001

10. Adam RZ. Do complete dentures improve the quality of life of patients? [minor thesis]. Cape Town: University of Western Cape; 2006. 